\title{
Measurement and Enhancement of Environmental Responsibility Level of an Energy Enterprise in the Context of Energy Transformation
}

\author{
Shanshan Hou, ${ }^{1}$ Liang Tang $\mathbb{D}^{2},{ }^{2}$ Jiuyang Xue, ${ }^{2}$ and Jingnan $\mathrm{Lu}^{2}$ \\ ${ }^{1}$ School of Marxism, Fuyang Normal University, Fuyang 236037, China \\ ${ }^{2}$ School of Business, Fuyang Normal University, Fuyang 236037, China \\ Correspondence should be addressed to Liang Tang; 1120821013@hhu.edu.cn
}

Received 28 May 2021; Revised 29 June 2021; Accepted 20 July 2021; Published 27 July 2021

Academic Editor: Daqing Gong

Copyright (C) 2021 Shanshan Hou et al. This is an open access article distributed under the Creative Commons Attribution License, which permits unrestricted use, distribution, and reproduction in any medium, provided the original work is properly cited.

Energy transformation requires energy producers to pursue energy conservation and emission reduction, control greenhouse gas (GHG) emissions, and produce and supply clean low-carbon energy. Based on the principle of balanced scorecard, this paper selects the data on China Shenhua Energy Company Limited (China Shenhua) of 2015-2019, systematically analyzes the influence of energy transformation on environmental protection effect of energy enterprises, and measures the environmental responsibility level (ERL). The results show that, in the context of energy transformation, Chine Shenhua always attaches great importance to ecoenvironment protection, vigorously develops clean, safe, and efficient energy, implements key tasks like green mine construction and ultra-low emission upgrading, promotes pollution control and ecoenvironment governance, takes measures of energy conservation and emission reduction, and continuously steps up the level of carbon emissions control, thereby steadily improving ecological civilization.

\section{Introduction}

Currently, the world is at a critical juncture of energy transformation. Facing common problems like energy shortage, environmental pollution, and climate change, all countries join hands to take consistent actions to curb global ecoenvironment degradation and promote green, low-carbon economic development through energy transformation [1], kicking off a worldwide energy revolution with the theme of developing and utilizing renewable energy [2].

China is the largest energy consumer, energy producer, and carbon emitter around the world. In 2019, China consumed $4.86 \times 10^{9}$ tce of primary energy, including $57.7 \%$ of coal, $18.9 \%$ of oil, $8.1 \%$ of natural gas, and $15.3 \%$ of nonfossil energy [3]. Over the years, China has been facing a heavy obligation of emission reduction, a tremendous environmental pressure, and a growing energy constraint. The energy development in China has several major problems: (1) the total energy consumption is constantly rising, calling for more efficient use of energy; (2) the energy structure is unreasonable, bringing a huge carbon emission pressure; (3) the ultra-high dependence on foreign energy threatens the energy security; (4) the traditional energy is oversupplied, the new energy develops slowly, and technical innovation is far from sufficient [4]. Under the current model of energy development, it is difficult to assure national energy security or promote coordinated development between economy, society, and environment, not to mention fulfilling the pledge to reduce greenhouse gas (GHG) emissions. Pushing forward green, low-carbon energy transformation is the obligation of China as a large responsible country and is the necessary path toward national energy security and environmental protection [5]. Under the target of carbon neutralization and carbon emission reduction, the "fourteenth five-year plan" should formulate quantitative targets by stages and strengthen the comprehensive coordination and connection among the targets. From the perspective of carbon neutralization in 2060, the systematic research on the 
implementation path of carbon neutralization target is carried out, and the quantitative target of carbon emission reduction by stages is proposed, which is compared with the existing targets in the fields of climate, energy, and environment, such as carbon intensity target, energy intensity target, nonfossil energy proportion target, renewable energy development target, total energy consumption control target, and coal consumption target. Carbon emissions can be used as an indicator to strengthen the coordination and cohesion between the goals.

The ruling party of China stressed in its work report of 2017 that China should revolutionize its energy production and consumption and forge a clean, low-carbon, safe, and efficient energy system. In 2016, China issued the Strategy for Energy Production and Consumption Reform, which elevates energy transformation to a national strategy for energy strategy revolution, calls for fundamental changes of energy production and consumption toward green, low-carbon pattern, and eyes a clean, low-carbon, safe, and efficient energy system that ensures the diversity of energy structure and safety of energy supply (Table 1). In September 2020, China announced that it will further increase its contribution to carbon reduction by peaking its carbon emissions before 2030 and neutralizing carbon emissions in 2060. In addition, the general plan of China for 2021-2025 also pointed out an important goal of socioeconomic development: making new progress on ecological civilization, further rationalizing the allocation of energy resources, and continuously suppressing the total emissions of main pollutants.

Under the dual pressures from the global initiative of carbon reduction and high-quality development of domestic economy, China has successively formulated several topdesign programs and government plans, which clearly specify the direction of energy transformation. In recent years, energy transformation in China has entered a new age, with enhanced ability to guarantee energy supply, prominent results on energy conservation and energy structure optimization, rapid progress on energy technology, and improved mechanism of energy governance.

So far, many scholars have theoretically analyzed the environmental effects of energy transformation on socioeconomic development $[6,7]$. But few have explored the environmental effects in specific enterprises in the context of energy transformation. Therefore, this paper chooses to systematically analyze how energy transformation affects the environmental effects of energy enterprises. Taking China Shenhua Energy Company Limited (China Shenhua) as an example, the authors enumerated the environmental responsibility of the enterprise under energy transformation, measured the fulfillment of that responsibility, i.e., the environmental responsibility level (ERL), and then presented strategies for the enterprise to further improve its ERL.

\section{Relevant Concepts and Theoretical Bases}

2.1. Energy and Energy Transformation. Energy refers to any resource that directly or indirectly provides the powers needed by humans, namely, light, heat, and momentum [8]. Energy lays the basis of human civilization and drives the growth of material wealth. Energy transformation is a fundamental change of main elements of energy system, such as energy form, energy technology, energy structure, and energy management, marking a trend from carbon to noncarbon in human energy utilization [9]. Energy transform is led by scientific innovation and technological progress. The change of energy technology is stimulated by our energy demand, in return, affects our production model, lifestyle, and social management, and promotes social development. From the perspective of civilization and social development, energy transformation directly propels civilization development and progress. Every energy transformation in history has boosted the productivity and facilitated social development. In many cases, the complex process of energy transformation is pathdependent rather than revolutionary and tends to be gradual instead of disruptive [10].

In recent years, the change of international energy system picks up speed, unveiling the third global energy transformation. Pioneered by energy technology revolution, the energy transformation is in full swing toward green, lowcarbon energy and energy conservation and emission reduction. The abandonment of carbon and fossil energy has become a clear trend [11]. The third global energy transformation will be driven by a new round of technological revolution and industrial revolution. The main elements of energy system will be fully renewed. The primary form of energy will change from fossil energy to new energy, completing the transfer from carbon to noncarbon. As for energy technology, the dominance of resource advantage in energy development will be replaced with technology. Further, secondary energy will topple primary energy as the dominator of energy structure.

2.2. Corporate Environmental Responsibility. Enterprises, as the main pollutant emitters, play an important role in environmental governance. Energy companies ought to bear ecoenvironmental responsibility, because they are creators of numerous ecoenvironment problems in energy development and utilization. These enterprises should strike a balance between energy development and utilization and environmental protection by reducing pollutant emissions and strengthening environmental protection. On this basis, they must fulfill the social responsibility of energy cleaning, promote the clean and efficient use of fossil energy, develop and utilize clean, low-carbon new energy, and develop lowcarbon energy economy [12-15].

Fulfilling environmental responsibility is not an economic investment. In the short term, this action could add to the operating cost of the enterprise and increase the constraint on liquidity. In the long run, however, this is highly necessary for the enterprise to realize sustainable development [16]. By actively undertaking its environmental responsibility, an enterprise can receive policy, financial, and social resources more easily. In addition to direct economic benefits, the enterprise fulfilling environmental responsibility will acquire a much stronger competitive advantage. The implicit economic benefits will greatly enhance the corporate value $[17,18]$. 
TABle 1: Proportions of different energies in China's energy transformation goal.

\begin{tabular}{lcc}
\hline Type of energy & 2020 & 2030 \\
\hline Clean energy & $15 \%$ & $20 \%$ \\
Natural gas & $10 \%$ & $15 \%$ \\
Coal & $<58 \%$ & $60 \%-65 \%$ (compared to 2005) \\
GHG emission reduction & $40 \%-50 \%$ (compared to 2005) & $>50 \%$ \\
\hline
\end{tabular}

2.3. Balanced Scorecard. Balanced scorecard is a new performance management system, which implements the organization's strategy as an operable measure and target value from the four perspectives of finance, customer, internal operation, and learning and growth. In the context of energy transformation, the public is more and more aware of the importance of environment to human survival and development, due to the increasingly serious environmental problems. Energy transformation requires humans to shift from the traditional resource-based development model to a novel technology-based innovation-driven development model. When it comes to ERL measurement, balanced scorecard can use quantitative indices to identify the keys and expose the defects of an enterprise in fulfilling its environmental responsibility. Then, the enterprise can take advantage of energy transformation to optimize its environmental management capability and better renovate its development model. Moreover, balanced scorecard describes the whole process of enterprise production and operation from multiple angles. With the aid of this technology, it is possible to select environmental management measures and environmental responsibility standards in advance, incorporate social responsibility management and environmental management to the daily management system of the enterprise, and provide stakeholders with different information at a low cost of communication.

\section{Green Empowerment: Environmental Effects of Energy Transformation on Energy Enterprise}

The increasingly severe climate change externally motivates energy enterprises to transform its energy strategy. Energy transformation requires energy producers to pursue energy conservation and emission reduction, control greenhouse gas (GHG) emissions, and produce and supply clean lowcarbon energy. In fact, the transformation of energy enterprise is the commercial connotation of energy transformation. Being the largest energy producer in China, China Shenhua mainly engages in coal production and power generation. The enterprise has been vigorously promoting the large-scale use of clean energy, the cleaning of fossil energy, and the intelligence of energy industry. Following the trend of energy revolution, the enterprise adheres to the principles of green, circulating, and low-carbon development, carries out key tasks like green mine construction and ultra-low emission upgrading, promotes pollution control and ecoenvironmental governance, implements energy conservation and emission reduction measures, and improves carbon emission control continuously, aiming to realize the goal of carbon peaking and neutralization, for example, the group's power plant to reduce power supply's coal consumption for technical improvement. The application of supercritical technology, system optimization, heating transformation, and other ways promotes carbon reduction and increases the unit load. In 2020, the coal consumption of power supply will be reduced by $1.4 \mathrm{~g} / \mathrm{kWh}$.

3.1. Improving Environmental System. In recent years, China Shenhua has witnessed a growing trend of ERL and constructed a stereoenvironmental management system, covering target planning, management system, and risk evaluation. In addition, the enterprise has established an efficient information management system, capable of collecting environmental data in an accurate and timely manner and ensuring the smooth communication with management targets.

3.1.1. Environmental Target Planning. China Shenhua has prepared a series of plans, including Special Planning for Environment, Society, and Governance (ESG) in Fourteenth Five-Year Plan Period, Development Plan for Energy Conservation and Environmental Protection in Fourteenth Five-Year Plan Period, and Three-Year Plan for Environmental Protection, which detail the development state and internal/external situation of the enterprise, identify the outstanding environmental problems, and, on this basis, establish strategies and goals of environmental development.

3.1.2. Environmental Management System. China Shenhua has formulated environmental management regulations like Administrative Measures for Environmental Protection and Environmental Protection Responsibility System, established a sound decision-making mechanism, and implemented and supervised the implementation of a three-level management system. Besides, the enterprise has promoted the certification of factory environmental system. By the end of 2020, a total of six subsidiaries passed the ISO14001 certification of environmental management system, five passed the ISO50001 certification, and one passed the ISO45001/OSHAS18001 certification.

3.1.3. Environmental Risk Management. China Shenhua has attached great importance to environmental risk identification and prevention. According to environmental risk features and risk control responsibilities, the production subsidiaries have fully recognized the risks of different levels, types, and disciplines, following the risk control regulations and workflow, actively checked and cleared hidden hazards, and effectively controlled risks from the aspects of organization, institution, technology, and emergency response. 
3.1.4. Informatization of Environmental Protection. China Shenhua has successfully informatized environmental protection, improved the real-timeliness, systematicity, and standardization of energy conservation and environmental protection, and realized the online monitoring, ecological remote sensing, and energy conservation and environmental protection monitoring of key subsidiaries and major pollution sources. In this way, the enterprise overcomes the inefficient manual operations, timely allocates tasks to objects, and ensures that energy management data are complete, accurate, and reliable.

3.2. Coping with Climate Change. Climate change is the common challenge to all countries. Every enterprise must shoulder the responsibility of controlling and reducing carbon emissions. China Shenhua has established a comprehensive governance system for the risks and opportunities of climate change and relied on the system to identify, evaluate, and manage such risks and opportunities. The enterprise has made a detailed plan for the climate strategy. Specifically, it includes building climate change risk assessment system, establishing carbon emission management system, formulating greenhouse gas emission reduction target system, formulating management plan to mitigate the impact of climate change, setting greenhouse gas emission reduction target based on SBTI, and gradually participating in supply chain carbon emission management. Besides, the enterprise has actively replaced original energy supply equipment with clean energy like solar power and wind power and gradually lowered the proportion of fossil energy in production, trying to effectively suppress GHG emissions.

To cope with the challenges of climate change, China Shenhua has taken the initiative to carry out technological innovation, promote energy conservation and emission reduction, and control GHG emissions. At the request of local governments, the key subsidiaries of energy consumption and emission control have managed and stored carbon assets, promoted the trade of carbon quota in market, and further improved carbon emission management. Furthermore, the enterprise has participated in the construction of China's carbon market and piloted the program in which every power plant must complete its annual carbon quota.

\subsection{Energy Conservation and Pollution Prevention. As} mentioned before, China Shenhua has formulated environmental management regulations like Administrative Measures for Environmental Protection and Environmental Protection Responsibility System, which require the observation of energy conservation throughout resource development and utilization, as well as the allocation and efficient use of clean energy in current businesses. In 2020, the enterprise consumed $1.6 \%$ fewer energy compared to the previous year. Comprehensive energy consumption of China Shenhua (10000 tons of standard coal) decreased from 4958.44 in 2018 to 4324.04 in 2020 . To reduce the dependence and influence on surface water and groundwater, China Shenhua has tried to reduce the water consumption under the current conditions, explored seawater desalination, construction water purification and reuse, and ballast water reuse technologies, broadened water channels, improved water use efficiency, and alleviated the pressure on water resources via multiple channels. In 2020, recycled water and other alternative water sources accounted for $17 \%$ of all water consumed by the enterprise. China Shenhua has also kept updating management concepts, management systems, and supervision measures and controlled pollution in a precise, scientific, and lawful manner, thereby meeting the requirements on pollutant emissions. In 2020, the enterprise invested a total of 996 million yuan in pollution control.

3.4. Ecological Repair and Biodiversity. During the operation, China Shenhua has predicted the possible environmental damage and impacts of its businesses and adopted concrete measures to mitigate and compensate for these damages. Several management regulations, namely, Administrative Measures for Environmental Protection and Conservation of Water and Soil, have been prepared to speed up the construction of green mines, the land reclamation in the mine area, and the land treatment in subsidence area, restore the local ecoenvironment, and increase carbon sink. These management regulations also highlight the importance of protecting biodiversity and biological habitat. In engineering construction and project operation, environmental evaluation requirements have been strictly enforced, and the environment has been constantly improved to enhance biodiversity. By the end of 2020, the company has basically constructed the ecological spatial structure of landscape, forest, field, lake, and grass. Among them, the cumulative ecological management area is 376 square kilometers, the vegetation coverage rate has increased from $3 \%$ to more than $64 \%$, the plant species has increased from 16 to nearly 100 , and the microbial and animal populations have also increased significantly. It reverses the degradation direction of the original fragile ecological environment and promotes the harmonious coexistence between man and nature.

\section{Index System and Measurement of ERL of the Energy Enterprise}

4.1. Balanced Scorecard-Based ERL Index System. Environmental responsibility indices generally measure how much the daily operations of an enterprise affect the environment. They are associated with the enterprise's business philosophy and relevant environmental policies and regulations, as well as stakeholders. Against the backdrop of energy transformation, the public has paid wide attention to environmental responsibility and its implementation of enterprises, thanks to the adoption of innovation-driven development strategy and the philosophy of sustainable development. For an energy enterprise, the pollution control must focus on the following issues: the ecological damage and solid waste pollution induced by energy mining and the air pollution and wastewater pollution generated by production. Taking China Shenhua as an example, this paper sets up an index system for the ERL to fully characterize the 
environmental influence of energy transformation on the enterprise. The index system covers indices in four dimensions: financial dimension, client dimension, internal business flow dimension, and learning and growth dimension (Table 2).

\subsection{Index Weighting Based on Entropy Method}

4.2.1. Normalization of Indices. Different types of indices need to be processed under different criteria. To ensure the consistency of evaluation results, this paper decides to normalize the selected indices. The normalization was mainly carried out by extreme value treatment.

Positive indices:

$$
V_{i j}=\frac{\left(X_{i j}-X_{i j}^{\min }\right)}{\left(X_{i j}^{\max }-X_{i j}^{\min }\right)} \quad i=1,2, \ldots, 5, j=1,2, \ldots, 18
$$

Negative indices:

$$
V_{i j}=\frac{\left(X_{i j}^{\max }-X_{i j}\right)}{\left(X_{i j}^{\max }-X_{i j}^{\min }\right)} \quad i=1,2, \ldots, 5, j=1,2, \ldots, 18 .
$$

Among all selected indices, there are only three negative indices: asset-liability ratio $X_{1}$, comprehensive energy consumption of raw coal production $X_{11}$, and death rate per million tons of raw coal $X_{16}$.

4.2.2. Calculation of Proportion of Variance Explained (PVE) by Each Index. The PVE of index $j$ in year $i$ can be calculated by

$$
P_{i j}=\frac{V_{i j}}{\sum_{i=1}^{m} V_{i j}} \quad i=1,2, \ldots, 5, j=1,2, \ldots, 18 .
$$

4.2.3. Calculation of Information Entropy and Utility of Each Index. Information entropy: $e_{j}=-(1 / \ln m) \sum_{i=1}^{m}$ $\left(P_{i j} \times \ln P_{i j}\right) \quad 0 \leq e_{j} \leq 1$.

Information utility: $d_{j}=1-e_{j} \quad i=1,2, \ldots, 5, j=$ $1,2, \ldots, 18$.

4.2.4. Calculation of Weight of Each Index and Dimension.

$$
W_{j}=\frac{d_{j}}{\sum_{j=1}^{18} d_{j}} \text {. }
$$

The values of the indices were obtained by collecting and sorting the raw data from the Corporate Social Responsibility Reports of China Shenhua in 2015-2019. Through the above steps, the weight of each index and dimension in the index system for China Shenhua's ERL was acquired (Table 3).

\subsection{ERL Measurement and Results Analysis}

\subsubsection{Measurement of China Shenhua's ERL.}

(1) Calculation of composite index for each evaluation index:

$$
f_{j}=W_{j} \sum_{i=1}^{5} V_{i j} \quad i=1,2, \ldots, 5, j=1,2, \ldots, 18 .
$$

(2) Calculation of composite index for the enterprise in each year:

$$
f_{j}=\sum_{j=1}^{18} W_{i j} V_{i j} \quad i=1,2, \ldots, 5, j=1,2, \ldots, 18 .
$$

4.3.2. Results Analysis. Based on the index weights of the index system and the raw data of China Shenhua in 2015-2019, the ERL of China Shenhua in 2015-2019 was obtained (Figure 1).

Overall, the composite index for the ERL of China Shenhua dropped from 0.4283 to 0.27898 in $2015-2016$, but exhibited a continuous growth from 2016 to 2019. In the broad context of China's energy transformation, China started to deepen energy reform in 2016, with the aim of solving the oversupply of traditional energy, removing the bottleneck of clean energy development, improving the operating efficiency of the energy system, and accelerating the supply-side reform of energy structure. Starting from that year, China Shenhua was reorganized with China Guodian Corporation, creating a new development model of energy enterprises. In the meanwhile, the enterprise carried out technological innovation, eliminated backward production capacity, and adhered to the concept of green development, forming an environmentally friendly development model of circular economy. These moves inject new vitality to the development of the enterprise. To sum up, the ERL of China Shenhua has been rising in the past five years.

As shown in Figure 2, almost all dimensions, except the financial dimension, declined in 2015-2016. This is consistent with the appearance of minimum total score in 2016 in Figure 1. Specifically, financial dimension and learning and growth dimension fluctuated relatively significantly. Since 2015, financial dimension has been increasing, indicating that, in terms of ERL, the overall financial performance of the enterprise increases with environmental investment; in other words, corporate environmental investment promotes financial performance in the context of energy transformation. Since 2016, a series of policies were released, forcing the enterprise to scale up efforts in energy intensification and carbon reduction and invest more in scientific R\&D and environment. As a result, the growth of the energy consumption of raw coal production clearly slowed down, mean recovery ratio of coal and comprehensive utilization of wastewater further increased, and carbon emissions significantly declined. 
TABLE 2: ERL index system of China Shenhua

\begin{tabular}{|c|c|c|}
\hline Criteria layer & Alternative layer & Index definition \\
\hline \multirow{6}{*}{ Financial dimension } & Asset-liability ratio $X_{1}$ & Year-end percentage of total liabilities to total assets \\
\hline & Return on assets $X_{2}$ & $\begin{array}{c}\text { Percentage of total mean profit to total mean assets before } \\
\text { interest and tax }\end{array}$ \\
\hline & Return on equity $X_{3}$ & Return on equity \\
\hline & Operating income $X_{4}$ & Operating income/million yuan \\
\hline & Total profit $X_{5}$ & Total profit/million yuan \\
\hline & Environmental investment $X_{6}$ & Environmental investment/million yuan \\
\hline \multirow[b]{2}{*}{ Client dimension } & $\begin{array}{l}\text { Total sales of electricity } X_{7} \\
\text { Total sales of coal } X_{8}\end{array}$ & $\begin{array}{l}\text { Total sales of electricity/billion } \mathrm{kWh} \\
\text { Total sales of coal/million tons }\end{array}$ \\
\hline & Proportion of top five clients in sales $X_{9}$ & $\begin{array}{c}\text { Proportion of sales income to top five clients in operating } \\
\text { income }\end{array}$ \\
\hline \multirow{4}{*}{$\begin{array}{l}\text { Internal business flow } \\
\text { dimension }\end{array}$} & $\begin{array}{c}\text { Temporary announcement } X_{10} \\
\text { Comprehensive energy consumption of raw } \\
\text { coal production } X_{11}\end{array}$ & $\begin{array}{l}\text { Number of temporary announcements } \\
\text { Total energy consumption of raw coal production/total } \\
\text { production of raw coal (kgce/ton) }\end{array}$ \\
\hline & Mean recovery ratio of coal $X_{12}$ & Mean recovery ratio of all coal mining areas \\
\hline & Comprehensive utilization of wastewater $X_{13}$ & Percentage of recycled wastewater produced in the current year \\
\hline & $\begin{array}{c}\text { Carbon reduction } X_{14} \\
\text { Research and development (R\&D) input } X\end{array}$ & $\begin{array}{l}\text { Carbon reduction in the current year/10,000 tons } \\
\text { R\&D fund in the current year/million yuan }\end{array}$ \\
\hline \multirow{3}{*}{$\begin{array}{l}\text { Learning and growth } \\
\text { dimension }\end{array}$} & Death rate per million tons of raw coal $X_{16}$ & $\begin{array}{l}\text { Casualty incurred in the mining of each million tons of coal/ } \\
100\end{array}$ \\
\hline & Number of trained employees $X_{17}$ & Number of employees attending various trainings \\
\hline & Proportion of graduate students $X_{18}$ & $\begin{array}{c}\text { Number of employees with postgraduate degree and above/ } \\
\text { total number of employees }\end{array}$ \\
\hline
\end{tabular}

TABLE 3: Weight of each index and dimension in the index system for China Shenhua's ERL based on balanced scorecard.

\begin{tabular}{|c|c|c|c|c|}
\hline Dimension & Index & Information entropy $\left(e_{j}\right)$ & Information utility $\left(d_{j}\right)$ & Weight $(\mathrm{w})$ \\
\hline \multirow{6}{*}{ Financial dimension } & Asset-liability ratio $X_{1}$ & 0.688719 & 0.311281 & 0.07125 \\
\hline & Return on assets $X_{2}$ & 0.793624 & 0.206376 & 0.047238 \\
\hline & Return on equity $X_{3}$ & 0.824276 & 0.175724 & 0.040222 \\
\hline & Operating income $X_{4}$ & 0.735822 & 0.264178 & 0.060469 \\
\hline & Total profit $X_{5}$ & 0.772584 & 0.227416 & 0.052054 \\
\hline & Environmental investment $X_{6}$ & 0.836332 & 0.163668 & 0.037463 \\
\hline \multirow{4}{*}{ Client dimension } & Total sales of electricity $X_{7}$ & 0.84332 & 0.15668 & 0.035863 \\
\hline & Total sales of coal $X_{8}$ & 0.808491 & 0.191509 & 0.043835 \\
\hline & Proportion of top five clients in sales $X_{9}$ & 0.828252 & 0.171748 & 0.039312 \\
\hline & Temporary announcement $X_{10}$ & 0.805697 & 0.194303 & 0.044475 \\
\hline \multirow{4}{*}{$\begin{array}{l}\text { Internal business flow } \\
\text { dimension }\end{array}$} & $\begin{array}{l}\text { Comprehensive energy consumption of raw } \\
\text { coal production } X_{11}\end{array}$ & 0.806461 & 0.193539 & 0.0443 \\
\hline & Mean recovery ratio of coal $X_{12}$ & 0.790948 & 0.209052 & 0.047851 \\
\hline & Comprehensive utilization of wastewater $X_{13}$ & 0.644333 & 0.355667 & 0.08141 \\
\hline & Carbon reduction $X_{14}$ & 0.731312 & 0.268688 & 0.061501 \\
\hline \multirow{4}{*}{$\begin{array}{l}\text { Learning and growth } \\
\text { dimension }\end{array}$} & Research and development (R\&D) input $X_{15}$ & 0.774362 & 0.225638 & 0.051647 \\
\hline & Death rate per million tons of raw coal $X_{16}$ & 0.855745 & 0.144255 & 0.033019 \\
\hline & Number of trained employees $X_{17}$ & 0.567741 & 0.432259 & 0.098941 \\
\hline & Proportion of graduate students $X_{18}$ & 0.523147 & 0.476853 & 0.109149 \\
\hline
\end{tabular}

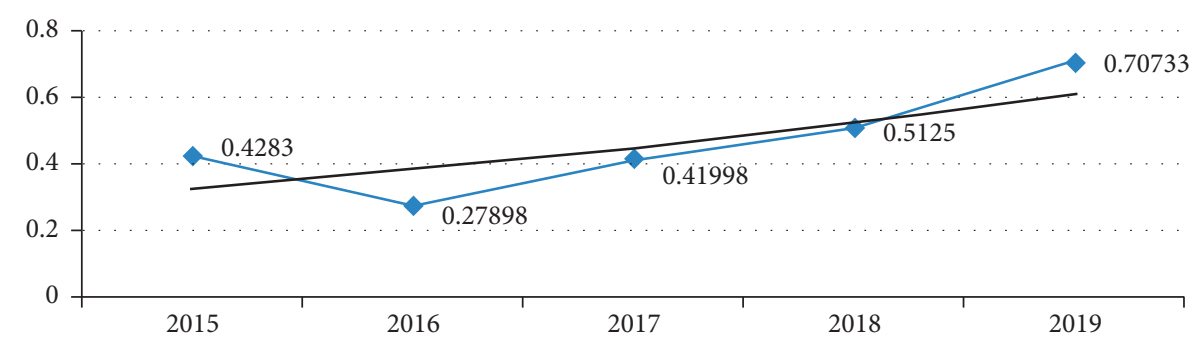

Figure 1: Composite index for the ERL of China Shenhua in 2015-2019. 


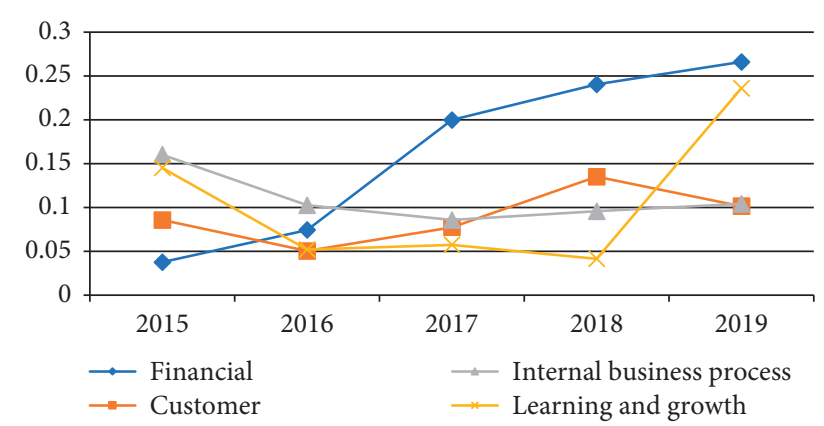

FIgURE 2: Composite index for ERL in each dimension of China Shenhua in 2015-2019.

\section{Conclusions}

To adapt to economic new normal, China has sped up the adjustment of energy structure, resulting in rising energy efficiency, improved energy structure, and reduced pollution emissions by industrial enterprises. However, the total energy consumption of industrial enterprises is still growing at a fast pace, posing a huge pressure on environmental bearing capacity. Taking China Shenhua as an example, this paper chooses 18 environmental responsibility indices and measures the ERL of the enterprise by entropy method. The results show that, in the context of energy transformation, China Shenhua always attaches great importance to ecoenvironment protection, vigorously develops clean, safe, and efficient energy, implements key tasks like green mine construction and ultra-low emission upgrading, promotes pollution control and ecoenvironment governance, takes measures of energy conservation and emission reduction, and continuously steps up the level of carbon emissions control, thereby steadily improving ecological civilization. The exploration provides energy enterprises with useful experience of transformation.

The research findings show that, in the context of energy transformation, that Chinese energy enterprises should adhere to the concept of green development and technical innovation, promote low-carbon transformation and environmental governance, and form an environmentally friendly development model for circular economy, injecting new vitality to the sustainable development of energy enterprises.

5.1. Accelerate Low-Carbon Transformation of Energy Enterprises in the Light of Historical Trend and Development Law. The increasingly severe climate change situation calls for immediate actions to speed up energy transformation. To complete energy transformation, energy producers must implement energy conservation and emission reduction, control GHG emissions, and produce and supply clean, lowcarbon energy. In January 2020, International Energy Agency mentioned in its report that the oil and gas industry needs to increase efforts to address climate change; in particular, the enterprises of the energy industry face the urgent need to adapt their operation and business model to energy transformation and climate effect. In February 2020,
Shell, Total, and British Petroleum (BP) all proposed their strategic plans to get to net zero, realizing the goal of net zero emissions and energy company transform by 2050 .

China Shenhua should strengthen cooperation with scientific institutions and government thinktanks, formulate strategic paths toward carbon peaking and neutralization, accelerate the development of new energy industries, build new highlights of clean energy, cultivate new growth poles, and lead the energy industry in the transformation campaign. A series of active measures should be taken to boost the cleaning of traditional energy and envisage the layout of new energy industry, such as to shape a development model of one pillar, two wings, and diverse elements. In addition, the enterprise should try every means to reduce energy consumption and realize green, innovative development.

\subsection{Establish a Scientific Management System for Internal/} External Environment and Realize Regular and Systematic Control of Environmental Risks. Scientific environmental management system is an effective tool for enterprises to plan for and implement environmental protection, enabling enterprises to make adjustment for specific conditions. The environmental management system needs to be adjusted timely according to the enterprise situation and energy market changes.

5.2.1. Environmental Supervision and Testing. China Shenhua should strictly implement the management system of pollutant discharge permit to discharge pollutants according to permit and carry out self-monitoring, information reporting, and information disclosure. The enterprise should also strictly implement the online monitoring management system of pollutants, strengthen the implementation of monitoring responsibility, standardize daily monitoring, establish monitoring and management ledger, and reinforce open management of monitoring results. In addition, the enterprise must step up walkdown and maintenance of online transmission equipment, perfect the walkdown and maintenance regulations for such equipment, and assure the continuous monitoring and accurate, effective data transmission for pollutant discharge.

5.2.2. Environmental Hazard Identification. China Shenhua should evaluate environmental impacts, formulate environmental risk identification standards for pollution sources, organize environmental supervision and review activities, and track and expedite rectifications required by environmental department of the government. The enterprise should divert more energy to investigation and correction of environmental hazards, prepare identification plans and management ledgers for environmental hazards of equipment, and regularly update the identification results.

5.2.3. Environmental Emergency Management. China Shenhua should perfect its procedure and plan for emergency management and design regular emergency drills against possible risk points, thereby reducing the 
environmental impacts of such hazards. Furthermore, the enterprise should formulate an emergency drill plan and organize standardized emergency drills, in order to test the emergency linkage mechanism and to realize quick and collaborative handling of environmental emergencies.

\section{Data Availability}

The data used to support the findings of this study are available from the corresponding author upon request.

\section{Conflicts of Interest}

The authors declare that they have no conflicts of interest.

\section{Acknowledgments}

This study was supported by Anhui Philosophy and Social Science Planning Project (AHSKQ2019D019).

\section{References}

[1] L. Ding and Q. Xia, "Empirical analysis on how financial development influences low-carbon economic gain efficiency considering the panel data of Yangtze River Economic Corridor," International Journal of Sustainable Development and Planning, vol. 15, no. 8, pp. 1251-1257, 2020.

[2] J. Z. Liu, Q. H. Wang, and F. Fang, "Data-driven-based application architecture and technologies of smart power generation," Proceedings of the CSEE, vol. 39, pp. 3578-3587, 2019.

[3] National Bureau of Statistics, China Statistical Yearbook of 2020, China Statistics Press, Beijing, China, 2020.

[4] J. Z. Liu, L. F. Ma, and Q. H. Wang, "Offshore wind power supports China's energy transition," Strategic Study of Chinese Academy of Engineering, vol. 23, no. 1, pp. 149-159, 2021.

[5] L. Zhu, W. Li, Y. Huang, and J. Li, "Spatiotemporal evolution and features of net carbon sink of farmland vegetation in Chongqing, China," International Journal of Sustainable Development and Planning, vol. 20, no. 2, pp. 219-226, 2020.

[6] J. A. Fuinhas, A. C. Marques, and M. Koengkan, "Are renewable energy policies upsetting carbon dioxide emissions? The case of Latin America countries," Environmental Science and Pollution Research, vol. 24, no. 17, pp. 15044-15054, 2017.

[7] Z. Aldeek, "Green architecture and sustainability in the complex transformation of the built urban environment in Jordan," International Journal of Design \& Nature and Ecodynamics, vol. 15, no. 1, pp. 113-120, 2020.

[8] S. P. Parker, Energy Encyclopedia, Cheng Huier, Science Press, Beijing, China, 1992.

[9] C. N. Zou, D. B. He, and C. Y. Jia, "Connotation and pathway of world energy transition and its significance for carbon neutral," Acta Petrolei Sinica, vol. 42, no. 2, pp. 233-247, 2021.

[10] B. K. Sovacool, "How long will it take? Conceptualizing the temporal dynamics of energy transitions," Energy Research \& Social Science, vol. 13, pp. 202-215, 2016.

[11] L. Wu, "The impact of new energy development on energy transition and geopolitics," Pacific Journal, vol. 29, no. 1, pp. $62-70,2021$.

[12] S. X. Mo and P. Zhang, "On the eco-environmental responsibility of energy enterprises from the perspective of green development," The Northern Literary Studies, vol. 5, pp. 54-65, 2020.
[13] J. Du, Q. Li, F. Qiao, and L. Yu, "Estimation of vehicle emission on mainline freeway under isolated and integrated ramp metering strategies," Environmental Engineering and Management Journal, vol. 17, no. 5, pp. 1237-1248, 2018.

[14] J. Du, F. Qiao, and L. Yu, "Temporal characteristics and forecasting of PM2.5 concentration based on historical data in Houston, USA," Resources, Conservation and Recycling, vol. 147, pp. 145-156, 2019.

[15] F. Aminsharei, S. M. Borghei, R. Arjomandi, J. Nouri, and A. Pendashteh, "Effects of various plants on treatment efficiency of horizontal subsurface flow constructed wetlands based on the hydraulic retention time," Environmental Engineering and Management Journal, vol. 18, no. 6, pp. 12011206, 2018.

[16] C. Liu and J. H. Zhang, "Environmental responsibility, firm heterogeneity and enterprise tax burden," Finance and Trade Research, vol. 31, no. 9, pp. 64-75, 2020.

[17] J. P. Charkham, "Corporate governance: lessons from abroad," European Business Journal, vol. 4, no. 2, 1992.

[18] IGE Outlook, Entering the Decade of Electric Drive, IGE Outlook, Mumbai, India, 2020. 